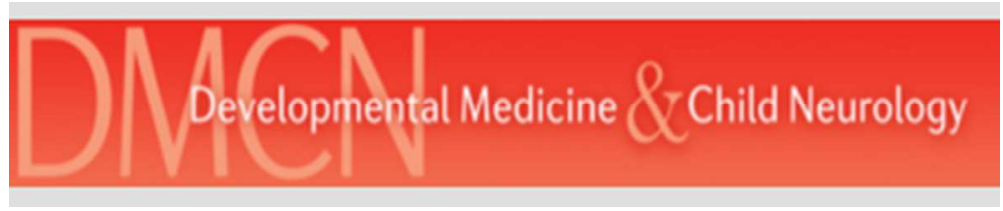

\title{
Mellow Parenting: systematic review and meta-analysis of an intervention to promote sensitive parenting.
}

\begin{tabular}{|r|l|}
\hline Journal: & Developmental Medicine \& Child Neurology \\
\hline Manuscript ID: & DMCN-IR-15-01-0023.R3 \\
\hline Manuscript Type: & Invited Review \\
\hline Date Submitted by the Author: & 22-Jun-2015 \\
\hline Complete List of Authors: & $\begin{array}{l}\text { MacBeth, Angus; University of Edinburgh, School of Health in Social } \\
\text { Science } \\
\text { Law, James; Newcastle University, School of Education, Communication } \\
\text { and Language Sciences } \\
\text { McGowan, Ian; University of Ulster, School of Nursing } \\
\text { Norrie, John; University of Aberdeen, CHaRT } \\
\text { Thompson, Lucy; University of Aberdeen, Centre for Rural Health } \\
\text { Wilson, Philip; University of Aberdeen, Centre for Rural Health }\end{array}$ \\
\hline Keywords: & \begin{tabular}{l} 
parenting, mellow parenting, meta analysis, outcomes, mental health \\
\hline
\end{tabular} \\
\hline
\end{tabular}

\section{SCHOLARONE ${ }^{\text {IM }}$ Manuscripts}


Abstract:

Aim: To review and meta-analyse Mellow Parenting (MP) interventions for parent-child dyads at high-risk of adverse developmental outcomes.

Method: Using PRISMA guidelines we extracted all published evaluations of MP and Mellow Babies (MB) programmes. We identified published studies with RCT, quasi-experimental or within-subject pre-post designs. We incorporated grey literature for unpublished publicly available evaluations. Effect sizes were calculated for impact of MP on parental mental health and child behaviour. Data were extracted on demographics, age of participants, country, and potential sources of bias.

Results: We identified eight papers, representing nine datasets, from which we calculated effect sizes from five. There was evidence of a medium treatment effect of MP compared to controls on maternal wellbeing and child problems. Drop-out from treatment was variable. However, data were heterogeneous and there was evidence of methodological bias.

Interpretation: Our data give some support to claims for effectiveness of MP as a group intervention for families with multiple indices of developmental adversity. Given the methodological weaknesses of literature in the area, novel approaches are needed in future trials of low-budget complex interventions in non-commercial settings.

What this paper adds: 2 bullet points ( 5 - 10 words)

- Mellow Parenting has medium effect sizes on parent/child outcomes.

- Data were subject to methodological limitations of small sample size.

- Synthesising evidence across methodologies may facilitate trials of noncommercial complex interventions. 


\section{Introduction:}

Social adversity and poor parental mental health confer vulnerability to long term negative effects on children's psychological, social, educational and economic outcomes (1-4). Exposure to early stress has deleterious effects on the development of infant stress regulation systems (5), leading to increased problematic behaviour with corresponding long-term implications for vulnerabilities in neurological and physical health (6). Parental risk factors include exposure to relational violence, parental mental ill health or problem drug use, teen parenthood, and multiple indices of social deprivation, someimte leading to social work involvement or child protection measures, , (7-10). The combination of maternal mental health, optimal parent-child attachment and parental sensitivity with contingent, developmentally appropriate parental responses to infant signals of distress or the need for stimulation, have been shown to be important for the development of infant attachment security and optimal childhood psychological development(11-13). Furthermore the use of parenting interventions in vulnerable groups $(14,15)$ has mixed effectiveness in reducing children's psychosocial problems.

Parenting programmes have achieved broad support as preventative interventions that may positively impact on childhood wellbeing. However, current intervention packages with a substantial evidence base such as Incredible Years (16) and the Triple P Programme (17) tend to focus on parental management of children's behaviour or are primarily targeted at families with children of two years and over. Attachment relationships and parental sensitivity - key psychological mechanisms for the transmission of resilience - are not the primary focus of these programmes (12). Although there is broad agreement that attachment-informed parenting programmes confer benefits with regard to developmental outcomes and parental sensitivity in vulnerable families with young children (18), such interventions tend to focus on parent-infant interaction without a corresponding emphasis on maternal mental health (19). Such an approach is likely to be limited in effectiveness because uptake of parenting interventions is lowest among parents with mental health problems (20). The Nurse-Family Partnership (NFP) adopts a different model (1), giving support to teenage mothers through a programme of home visitation spanning the antenatal period and the first two years of a child's life. It appears to have long-term effectiveness ${ }^{1}$ but is costly and has a target group restricted to teenage first-time mothers attending for antenatal care before the third trimester.

The "Mellow Parenting" (MP) intervention has been developed as an alternative, attachment-informed suite of interventions specifically targeted at parents of children from 0-8 years of age at high risk of adverse outcomes because of parental difficulties. It includes an emphasis on developing parental sensitivity and attunement recommended by previous meta-analyses of attachment-related interventions (12) but also incorporates components emphasizing both parental mental health (cognitive behavioural strategies techniques for ameliorating parental depression and anxiety) and the parent-child relationship; is groupbased, includes provision for strategies to enhance engagement (transport and crèche provision); and can be delivered by non-specialists (albeit with 
experience of work with young children and their families) with minimal training. Ongoing supervision is provided to practitioners and is essential for accreditation as a practitioner. Use of video feedback and interactive tasks are key to programme delivery, consistent with best-practice in evidence based parenting (12). MP was initially developed for use in children under age five years (MP), but has subsequently, without deviating from the core intervention format been adapted for use with infants (Mellow Babies, MB), antenatally (Mellow Bumps) and with fathers (Mellow Dads). MP and MB have rapidly gained support with early years practitioners and has been recommended in UK national guidelines for evidence-based parenting interventions and the California Evidence-Based Clearinghouse for Child Welfare (http://www.cebc4cw.org/program/mellow-babies/) but much of this evidence is derived from small-case studies (21) and qualitative studies (22-24). There is therefore a disjunction between positive representations of MP in practitioner reports and policy guidance, compared with the relative lack of outcome driven clinically informed research, such as adequately powered randomised trials

More broadly there are also general difficulties in moving plausible nonpharmaceutical interventions towards evaluation in definitive randomised controlled trials. Trial sample size calculations conventionally require one or more exploratory randomised trials of adequate size and it is difficult to gain external research funding for such exploratory trials: few non-commercial developers of interventions for children have the resources to obtain the results they need.

To address both the limitations of the evidence base for MP and its variations and the broader issue of developing evaluation mechanisms for non-commercial complex interventions we present a synthesis of data from a number of small randomised controlled trials (RCTs), quasi-experimental and within-subject evaluations to generate an estimate of an expected effect size for MP.

\begin{abstract}
Aims and Hypotheses:
The primary aim of the current review was to review and meta-analyse maternal and child outcomes for the MP programme, with a view to generating effect size estimates for these outcomes. A secondary aim was to assess systematically, and where possible statistically, methodological limitations of the current evidence base for MP. We were aware that a sizeable proportion of available data on MP is contained within a 'grey' literature.
\end{abstract}

We hypothesised that participation in a MP group would be associated with a) improved parental mental health and b) a reduction in child problem behaviour at post group evaluation, compared to baseline. In addition, we hypothesised that the effect size for improvements in parental mental health and child outcomes would be greater than the corresponding effect for control groups (where available).

\title{
Methods:
}

Protocol and Registration

We did not register a protocol for the meta-analysis. 


\section{Eligibility criteria and Information sources:}

Our eligibility criteria for the meta analysis were as follows:

- Project evaluated outcome for the MP programme.

- Outcomes were described for a defined variable (e.g. maternal depression,) using a validated outcome measure (e.g. Adult Wellbeing Scale).

Articles published or available online between 1990 - 2014 were eligible for inclusion.

\section{Search Strategy and Information sources:}

A search was carried out on $7^{\text {th }}$ July 2014. The search was conducted using conjunctions of the following search terms: Mellow AND toddler* OR bab* OR parent* OR dad* OR mum* The following online databases were systematically searched in order to identify relevant studies: Web of Science, CINAHL, PsycINFO, MEDLINE. In addition, we searched the grey literature using the following approaches. First, we used the reference lists of published papers. Second, Google Scholar search was used for published reports available in the public domain. This included data available in the form of reports or other unpublished data where reference to the data could be obtained through a standard Google search. Finally, where necessary, authors were contacted for additional information on the data set.

\section{Study selection and data collection:}

The first author performed the initial search and extraction of 'grey literature'. Queries regarding eligibility were resolved by discussion between two of the authors (PW and AM). For eligible studies, data were collected, with permission, onto a form adapted from that used by the Scottish Intercollegiate Guideline Network(24). One of the authors (PW) has used this procedure in a review of the Triple $P$ parenting programmes (17).Two authors (AM, IM) performed independent data extraction. If authors disagreed, a third author adjudicated.

| The study selection process is displayed in Supplemental Figure 1(online only).

\section{[Supplemental-Figure 1: PRISMA flow diagram]}

\section{Data items}

The following variables were assessed:

Numbers of patients or families included in the study

Location of study

Main characteristics of the patient population (including case mix)

Nature of the intervention being investigated

Which outcomes were compared across groups /between time points

Nature of the control or comparison group (where applicable)

Length of follow-up (if any)

Nature of child-based outcome measure(s) used in the study

Parental mental health outcomes

Study design (RCT/wait-list control/pre-post comparison) 
If treatment comparison, was there a waiting list design?

Whether the assignment of subjects to treatment groups was randomized Whether reporters of the child-based outcomes were blind to treatment allocation

Dropout rates for participants recruited into each arm of the study

Mean and standard deviation of post-intervention child-based outcome measures (for meta-analysis)

Mean and standard deviation of post-intervention parental mental health outcome measures (for meta-analysis)

Whether a statement of study funding was included

Whether a conflict of interest statement was include

We also classified studies according to AACPDM Levels of Evidence (25)

\section{Analyses:}

The effect size (ES) for each study included in the meta-analysis was estimated using the standardized mean difference (SMD), with post-intervention mean and pooled standard deviation. Hedges $g$, under a random effects modelling approach, was used to obtain unbiased estimates of ESs. Due to the small number of studies and assumption of between study heterogeneity, random effects modeling was applied. Variation in SMDs attributable to heterogeneity was assessed with the I-squared statistic (the percentage of between-study heterogeneity attributable to variability in the true treatment effect, rather than sampling variation). Risk of bias was assessed descriptively using the above checklist items.

\section{Results:}

\section{Study Characteristics:}

After extraction of papers three studies were excluded as only presenting qualitative or case study data $(21,23,26,27)$ consistent with Level V of AACPDM guidelines. All studies presented in Table 1 met level III or IV of AACPDM levels of evidence. The studies in our final data set included four waiting list controlled trials (28-31), one study which proposed a stepped wedge design, but for which only treatment group data were available (32); and four within-subjects evaluations evaluating MP for Reactive Attachment Disorder (22) and evaluating MP in routine care(33). Data were reported for studies from Scotland, Northern Ireland, Russia, and New Zealand. For the Russian, New Zealand and Northern Irish datasets $(28,29,32)$ we requested additional data from the authors due to insufficient detail in the source material. Due to insufficient data we were unable to include the Northern Irish datasets in the meta analysis but retain them in the review.

The total sample consisted of outcome data on $n=95$ parent-child dyads and $\mathrm{n}=55$ control dyads. The majority of data sets reported outcomes for MP although two samples evaluated Mellow MB $((28,30))$. The parental data identified in the systematic review related exclusively to maternal outcomes: no outcome data for fathers were available. Child outcome data were available from three of the studies (31). Measures were mainly taken at baseline prior to 
intervention commencing and at intervention end. Two studies provided followup data at 3-months ((34)) and 1 year post group (31) but due to the paucity of data we did not incorporate follow-up into the meta-analysis.

\section{Measures}

All studies papers included in the meta-analysis included a measure of maternal mental wellbeing pre- and post- treatment. There was some variability in the measures used (see Table 1), however all maternal health measures reported scores for depression as either scale or subscale scores. With regard to child psychological functioning, $n=4$ studies reported a measure of childhood difficulties using a parent-reported checklist. Again, all these measures incorporated a score for childhood problems as either the scale or a subscale of the total score. Therefore we were able to derive standardised scores for both maternal health and child outcomes. We note that 3 studies used a motherparent interaction measure, but reporting of the data was too heterogeneous to permit analysis of outcome $(17,18,24)$.

\section{INSERT TABLE 1 HERE}

\section{Risk of bias within studies}

Risk of bias characteristics are summarised in Supplemental Table $\underline{1 z}$. To our knowledge no studies in the review were registered with a national or international trials registry. No conflict of interest declarations were found. The data from two studies $(21,22)$ were reported within a book chapter and the evaluations from the Northern Irish Southern Health \& Social Care Trust (33) were routine data.

With regard to methodology, individual randomisation to treatment was reported in one study $(28,29)$; the remainder of studies were explicitly reported as quasi-experimental or within-subjects evaluations. Outcome measures were either collected by facilitators $(33,34)$ or not clearly reported. Consequently, there is a risk of bias with regard to reporting. With regard to negative findings, Puckering (22) reported that in its current delivery model MP was unlikely to benefit children presenting with RAD. Drop-out rates are recorded in Table 2. Drop-out rate from start to conclusion of treatment for MP/MB ranged from $0 \%$ to $29 \%$, whereas the control drop-out rate (where recorded) ranged from $4 \%$ to $34 \%$. We note that drop-out rates for both treatment and control groups were not recorded in the Russian samples $(28,29)$.

No intention to treat analyses were reported and the datasets contained insufficient numbers for sub-group analyses.

\section{INSERT TABLE 2 AND SUPPLEMENTAL TABLE 1\&Z HERE}

\section{Results of individual studies.}

Mean scores and standard deviations for the studies included in the meta| analysis are reported insupplemental Table 2. Data are therefore reported for treatment completers only. With regard to the quasi-experimental studies 
Puckering et al (1999) (31)used a comparison group of families attending Family Centres not offering MP; for the Russian studies $(28,29)$ control groups were other families attending Family Centres but on the waiting list for MP/MB. Finally, the control group for the Puckering et al (2010) MB study (30) received treatment as usual (TAU), whereas mothers in the treatment group received TAU $+\mathrm{MB}$.

\section{Synthesis of results}

Results for maternal mental health and childhood outcomes are presented in | Figures_-21 1 즐. Due to small sample sizes, results for MP and MB are combined. The weighted mean effect size for change in parental mental health for cases vs controls was $d=-0.67(95 \% \mathrm{CI}=-1.26$ to -0.21$)$ indicative of a medium effect size for improvement in maternal mental health. For child outcomes the weighted mean effect size for change in child problems for cases vs controls was $\mathrm{d}=-0.40$ ( $95 \% \mathrm{CI}=-0.77$ to -0.02 ) indicative of a medium effect size for reduced childhood problems. There was evidence for medium levels of heterogeneity in the parental data $\left(X^{2}=10.93, d f=4, p=0.027 ; I^{2}=63.4 \%\right)$. There was no evidence of heterogeneity for child data $\left(X^{2}=0.38, d f=2, p=0.827 ; I^{2}=0 \%\right)$. However, sample size was small. We repeated the analyses incorporating the pre-post treatment evaluations into the effect size estimate with no change in the pattern of results. Analyses using Eggers Test, funnel plots and Trim-and-Fill procedures indicated the absence of publication bias, small study effects or undue influence of individual studies.

\section{Discussion}

Our meta-analysis presents the first quantitative synthesis of results for the MP programme of parenting interventions. These associations were of medium effect size suggesting that participation in an MP programme was associated with improvements in maternal wellbeing and a reduction in child behaviour problems, albeit with a small and heterogenous sample of studies. Retention rates were favourable for participants who received the intervention. We note that the statistical analyses indicatedre was-no evidence of publication bias or small study effects. However, due to the heterogeneous nature of the included studies and the small sample sizes we urge although caution is needed in interpreting this finding because of the small sample sizes (35). Additionally, there remains the possibility of unpublished negative findings,

Therefore, However, we suggest that this pattern of results has important implications for building the evidence base for MP, for implementing MP in practice and also for developing evaluation mechanisms for non-commercial complex interventions (36). Given the lack of high-quality RCTs we suggest these data identify the need for one or more adequately powered RCTs of Mellow Parenting.

We note that the meta-analysis has several limitations, some of which we suggest are instructive in improving evaluation frameworks for complex interventions. The studies retrieved were small in number and within-studies the sample sizes were small. Study quality corresponded to Level III or IV levels of evidence, suggestive of the need for further high-quality research in this area. This is also 
possibly a reflection of the complexity in conducting research in families considered to be at developmental 'high-risk'. We are aware of two further studies for which outcomes are not yet published, one completed pilot trial of the Mellow Bumps antenatal intervention (clinicaltrials.gov NCT01590212) and an ongoing trial comparing antenatal Mellow Parenting with Triple P (ISRCTN21656568).

Data were heterogenous, reflected in the $\mathrm{I}^{2}$ values for change in maternal mental health. There were also gaps in the data with regard to sample characterisation and outcome data. We note that recording of drop-out rates, both prior to intervention and within intervention, was rather variable. Consequently we were unable to conduct any adequate drop out analyses, nor can we exclude the possibility of a biased drop out profile. We were unable to retrieve data for dropout rates prior to intervention but this suggests that there could be improvements in the pathway by which families who might benefit from MP are identified and engaged in services. A further statistical limitation was the lack of intention to treat analyses in these studies, adding a further note of caution to our analyses.

Furthermore, theThe small number of studies prevented analysis of the different variants on the MP base programme (e.g. MB, Mellow Bumps). Similarly, small sample size limited the data on long-term follow-up beyond end of intervention. Therefore, our data are silent on whether MP confers long-term developmental benefits to children: this deficit is equally evident in relation to all postnatal parenting interventions with children under three years (37). There were also limited data on mother-infant interaction, and no reporting of standardised parenting measures. Finally, we note that there were multiple indicators of potential bias within studies, such as failure to blind raters, some developer involvement and lack of declaration of conflicts of interests. To an extent this can be explained by the lack of RCTs in the synthesis and consequently lower standards of methodological rigour.

Turning to the implications of our meta-analysis we suggest that our findings support the evidence from single case and narrative reviews of MP that a groupbased, attachment-informed intervention can be effectively targeted towards parent-child dyads at risk of serious adverse outcomes resulting from parental difficulties. The baseline samples for all studies included in the meta-analysis had multiple indicators for developmental risk (including social adversity, exposure to interpersonal violence, parental substance misuse, parental mental illness or previous statutory social service involvement). Importantly, the results suggest the evidence of benefit from MP may be shared across both parents and offspring, consistent with findings from other attachment - informed programmes such as Incredible Years (16) and Family-Nurse Partnership (1). The review suggests that MP occupies a unique place with attachment informed parenting programmes in its explicit focus on families with substantial difficulties, its time limited nature, its group-based approach and its flexibility in age range. 
The results give tentative support to the existing position in the UK where MP is recommended in national guidelines as an early years intervention. The metaanalysis improves the evidence base by applying a degree of methodological rigour to this evidence base. We suggest that this has important implications for developing MP in routine practice. MP and other programmes involving parents and young children would benefit from a clear, standardised set of outcome measures focussed on tracking pre-post change in maternal (parental) mental health, indicators of child social, emotional and linguistic development, (38-41) and perhaps parent-infant interaction (11). As MP training is delivered through an international network of trainers there is scope for developing a routine framework for this intervention. A parallel example from clinical interventions in adult mental health is the increasing use of standardised outcomes used in Mentalization-based Therapy (42).

Our results demonstrate the challenges and opportunities for developing evaluations of complex interventions. This analysis identified a substantial grey literature reporting Mellow Parenting outcomes - in terms of commissioned reports, small-scale studies and conference presentations. Despite substantial efforts we were unable to use much of the data because of ethical barriers to using unpublished data for which research ethical consent may not have been sought. MP is therefore in the uncomfortable position where there is dissemination of the intervention in routine practice, with some collection of routine evaluation data, but without peer-reviewed or publicly available access to these data. We suggest that this requires a change in how we approach the use of routine data. MP is an example of an intervention that targets hard-to-engage families and sometimes the gathering of explicit consent for anonymised data collection may be unduly burdensome. One consequence of this is that families with substantial parenting difficulties may remain under-represented in the research literature (37). It may in some circumstances be appropriate to approach informed consent for (non-randomised) evaluation of these interventions from a community rather than individual perspective, as has been recommended for health services research more generally (36), and in these circumstances independent research ethics review should be sought whenever feasible. In tandem this requires: transparency from practitioners that routine anonymised data may be used to develop the knowledge base supporting the intervention; the use of outcome measures which are not burdensome; and robust systems for ensuring anonymisation of data. Similar ethical considerations have been applied to the use of family practice data for pharmaceutical post-marketing surveillance. As we move to increasing stratification of interventions to target subsets of a population likely to derive greatest benefit from a given treatment (36) this may be an effective approach to the provision of an exploratory evidence base for complex interventions in the non-commercial sector.

Conclusions:

Our meta-analysis of MP suggests the intervention confers medium level treatment effects to mothers and children presenting with multiple indices of environmental adversity threatening good developmental outcomes, albeit with 
some methodological weaknesses. We suggest that further research in this area should focus on better specification of the child development factors most likely to be improved (eg language acquisition (43)) and on delineation of the effectiveness of specific parenting programmes. To achieve this, we suggest increased reliance on routine data evaluation will be required.

\section{References}

1. Olds D, Henderson CR, Jr., Cole R, Eckenrode J, Kitzman H, Luckey D, et al. Long-term effects of nurse home visitation on children's criminal and antisocial behavior: 15-year follow-up of a randomized controlled trial. Jama. 1998;280(14):1238-44.

2. Coyle D, Alexander W, Ashcroft B. New Wealth for Old Nations: Scotland's Economic Prospects: Princeton University Press; 2005.

3. Kim-Cohen J, Moffitt TE, Taylor A, Pawlby SJ, Caspi A. Maternal depression and children's antisocial behavior: nature and nurture effects. Archives of general psychiatry. 2005;62(2):173-81.

4. Phillips DA, Shonkoff JP. From Neurons to Neighborhoods:: The Science of Early Childhood Development: National Academies Press; 2000.

5. Schore AN. Affect Dysregulation and Disorders of the Self (Norton Series on Interpersonal Neurobiology): WW Norton \& Company; 2003.

6. O'Connor TG. Maternal antenatal anxiety and children's behavioural/emotional problems at 4 years: Report from the Avon Longitudinal Study of Parents and Children. The British Journal of Psychiatry. 2002;180(6):502-8.

7. Caspi A, McClay J, Moffitt TE, Mill J, Martin J, Craig IW, et al. Role of genotype in the cycle of violence in maltreated children. Science. 2002;297(5582):851-4.

8. Wilson P, Bradshaw P, Tipping S, Henderson M, Der G, Minnis H. What predicts persistent early conduct problems? Evidence from the Growing Up in Scotland cohort. Journal of epidemiology and community health. 2013;67(1):7680 .

9. Halligan SL, Murray L, Martins C, Cooper PJ. Maternal depression and psychiatric outcomes in adolescent offspring: a 13-year longitudinal study. Journal of affective disorders. 2007;97(1-3):145-54.

10. Biederman J, Faraone SV, Monuteaux MC, Feighner JA. Patterns of alcohol and drug use in adolescents can be predicted by parental substance use disorders. Pediatrics. 2000;106(4):792-7.

11. Puckering C, Allely CS, Doolin O, Purves D, McConnachie A, Johnson PC, et al. Association between parent-infant interactions in infancy and disruptive behaviour disorders at age seven: a nested, case-control ALSPAC study. BMC pediatrics. 2014;14(1):223.

12. Bakermans-Kranenburg MJ, van IMH, Juffer F. Less is more: meta-analyses of sensitivity and attachment interventions in early childhood. Psychological bulletin. 2003;129(2):195-215.

13. Barlow J, McMillan AS, Kirkpatrick S, Ghate D, Barnes J, Smith M. Health Led Interventions in the Early Years to Enhance Infant and Maternal Mental 
Health: A Review of Reviews. Child and Adolescent Mental Health. 2010;15(4):178-85.

14. Schappin R, Wijnroks L, Venema MU, Wijnberg-Williams B, Veenstra R, Koopman-Esseboom C, et al. Primary Care Triple P for parents of NICU graduates with behavioral problems: a randomized, clinical trial using observations of parent-child interaction. BMC pediatrics. 2014;14(1):305.

15. Kleefman M, Jansen DE, Stewart RE, Reijneveld SA. The effectiveness of Stepping Stones Triple P parenting support in parents of children with borderline to mild intellectual disability and psychosocial problems: a randomized controlled trial. BMC medicine. 2014;12(1):191.

16. McGilloway S, NiMhaille G, Bywater T, Leckey Y, Kelly P, Furlong M, et al. Reducing child conduct disordered behaviour and improving parent mental health in disadvantaged families: a 12-month follow-up and cost analysis of a parenting intervention. European Child \& Adolescent Psychiatry. 2014:1-12. 17. Wilson P, Rush R, Hussey S, Puckering C, Sim F, Allely CS, et al. How evidence-based is an 'evidence-based parenting program'? A PRISMA systematic review and meta-analysis of Triple P. BMC medicine. 2012;10:130.

18. Barlow J, Smailagic N, Ferriter M, Bennett C, Jones H. Group-based parenttraining programmes for improving emotional and behavioural adjustment in children from birth to three years old. Cochrane Database of Systematic Reviews. 2010;3.

19. Murray L, Cooper PJ, Wilson A, Romaniuk H. Controlled trial of the shortand long-term effect of psychological treatment of post-partum depression: 2 . Impact on the mother-child relationship and child outcome. British Journal of Psychiatry. 2003;182:420-7.

20. NICE. Antisocial behaviour and conduct disorders in children and young people: recognition, intervention and management (guidance.nice.org.uk/cg158). 2013.

21. Puckering C, Evans J, Maddox H, Mills M, Cox AD. Taking Control: A Single Case Study of Mellow Parenting. Clinical child psychology and psychiatry. 1996;1(4):539-50.

22. Puckering C, Connolly B, Werner C, Toms-Whittle L, Thompson L, Lennox J, et al. Rebuilding relationships: a pilot study of the effectiveness of the Mellow Parenting Programme for children with Reactive Attachment Disorder. Clinical child psychology and psychiatry. 2011;16(1):73-87.

23. Birtwell B, Hammond L, Puckering C. 'Me and my Bump': An interpretative phenomenological analysis of the experiences of pregnancy for vulnerable women. Clinical child psychology and psychiatry. 2013.

24. Gifford-Sawyer M, Baghurst P. The use of a computer-assisted interview to administer the Child Behavior Checklist in a child psychiatry service. Journal of the American Academy of Child and Adolescent Psychiatry. 1991;30(4):67481.

25. Darrah J, Hickman R, O’Donnell M, Vogtle L, Wiart L. AACPDM methodology to develop systematic reviews of treatment interventions (Revision 1.2). Milwaukee, WI, USA: American Academy for Cerebral Palsy and Developmental Medicine. 2008.

26. Breustedt S, Puckering C. A qualitative evaluation of women's experiences of the Mellow Bumps antenatal intervention. British Journal of Midwifery.

2013;21(3):187-94. 
27. Puckering C, Rogers J, Mills M, Cox A, Raff MMG. Process and evaluation of a group intervention for mothers with parenting difficulties. Child Abuse Review. 1994;3(4):299-310.

28. Borjeson B. BS, Dovbnya S., Morozova T., Puckering C. Early Relationships and Child Development: Peter Publishing Company; 2008.

29. Morozova T. DS, Britten S., Puckering C. Early Relationships or What Babies Needs: Rech Publishing Company; 2011.

30. Puckering C, McIntosh E, Hickey A, Longford J. Mellow Babies: A group intervention for infants and mothers experiencing postnatal depression. Counselling Psychology Review. 2010;25(1):28-40.

31. Puckering C, Mills M, Cox A, Maddox H, Evans J, Rogers J. Improving the Quality of Family Support: An Intensive Parenting Programme: Mellow Parenting. The Department of Health, London, UK. 1999.

32. Penehira M, Doherty L. Tu mai te oriori, nau mai te hauora! A Kaupapa Māori Approach to Infant Mental Health: Adapting Mellow Parenting for Māori Mothers in Aotearoa, New Zealand. Pimatisiwin. 2013;10(3):367.

33. Trust SHC. Mellow Parenting Evaluation 2010-2011.

34. Doherty L. Hoki Ki Te Rito - Oranga Whanau Parenting For Indigenous Community in Aotearoa NZ. Infant mental health journal. 2014;35(3).

35. Coyne J, Kwakkenbos L. Triple P-Positive Parenting programs: the folly of basing social policy on underpowered flawed studies. BMC Medicine.

2013;11(1):11.

36. Campbell NC, Murray E, Darbyshire J, Emery J, Farmer A, Griffiths F, et al. Designing and evaluating complex interventions to improve health care. Bmj. 2007;334(7591):455-9.

37. Barlow J, Smailagic N, Ferriter M, Bennett C, Jones H. Group-based parenttraining programmes for improving emotional and behavioural adjustment in children from birth to three years old (Review): The Cochrane Library; 2012 2012.

38. Sim F, John O, Thompson L, Law J, Macmillan S, Affleck M, et al. Language and social/emotional problems identified at a universal developmental assessment at 30 months. BMC pediatrics. 2013;13(1):206.

39. Hutchings J, Bywater T, Daley D, Gardner F, Whitaker C, Jones K, et al. Parenting intervention in Sure Start services for children at risk of developing conduct disorder: pragmatic randomised controlled trial. Bmj.

2007;334(7595):678.

40. Landry SH, Smith KE, Swank PR. Responsive parenting: establishing early foundations for social, communication, and independent problem-solving skills. Developmental psychology. 2006;42(4):627.

41. Heckman JJ. Giving kids a fair chance: Mit Press; 2013.

42. Bales D, van Beek N, Smits M, Willemsen S, Busschbach JJ, Verheul R, et al. Treatment outcome of 18-month, day hospital mentalization-based treatment (MBT) in patients with severe borderline personality disorder in the Netherlands. Journal of personality disorders. 2012;26(4):568-82.

43. Allely CS, Puckering C, Mills M, Cox AD, Evans J, Maddox H. The Impact of the Mellow Parenting Programme on Later Measures of Childhood Verbal IQ. . Journal of Educational and Child Psychology. 2014;31(4):28-37. 


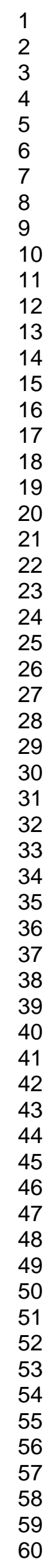

Mac Keith Press 
MP meta analysis

Draft 3.2

09/03/14

Table 1: Main Characteristics of included studies

4

5

\begin{tabular}{|c|c|c|c|c|c|c|c|c|c|c|c|c|c|c|}
\hline \begin{tabular}{l|}
6 ocation \\
7 \\
8 \\
9 \\
10
\end{tabular} & $\begin{array}{l}\text { Study } \\
\text { Type }\end{array}$ & $\begin{array}{l}\text { Level of } \\
\text { Evidence* }\end{array}$ & $\begin{array}{l}\text { Sample } \\
\mathrm{n} \\
\text { (control } \\
\mathrm{n} \text { ) }\end{array}$ & Patient characteristics & $\begin{array}{l}\text { Cases } \\
\text { Mean } \\
\text { age of } \\
\text { child in } \\
\text { months } \\
\text { (s.d.) }\end{array}$ & $\begin{array}{l}\text { Cases } \\
\text { Mean } \\
\text { age of } \\
\text { mothers } \\
\text { in years } \\
\text { (s.d.) }\end{array}$ & $\begin{array}{l}\text { Controls } \\
\text { Mean } \\
\text { age of } \\
\text { child in } \\
\text { months } \\
\text { (s.d.) }\end{array}$ & $\begin{array}{l}\text { Controls } \\
\text { Mean } \\
\text { age of } \\
\text { mothers } \\
\text { in years } \\
\text { (s.d.) }\end{array}$ & $\begin{array}{l}\text { Intervention } \\
\text { (MP/MB) }\end{array}$ & $\begin{array}{l}\text { Group } \\
\text { comparison }\end{array}$ & $\begin{array}{l}\text { Control } \\
\text { group }\end{array}$ & $\begin{array}{l}\text { Parental } \\
\text { Mental } \\
\text { Health } \\
\text { outcome } \\
\text { Measure }\end{array}$ & $\begin{array}{l}\text { Child - } \\
\text { based } \\
\text { outcome } \\
\text { Measure }\end{array}$ & $\begin{array}{l}\text { Interactic } \\
\text { measure }\end{array}$ \\
\hline $\begin{array}{l}11 \\
\text { Forth Valley, } \\
\text { Scotland } 17,25 \\
13 \\
14 \\
15 \\
16 \\
17 \\
18 \\
19\end{array}$ & $\begin{array}{l}\text { Case- } \\
\text { Control }\end{array}$ & III & $45(23)$ & $\begin{array}{l}\text { Families with child } \\
\text { under } 5 \text { with child } \\
\text { protection concerns, } \\
\text { persistent violence, } \\
\text { relationship } \\
\text { difficulties, mental } \\
\text { disorder, child } \\
\text { behavioural/emotional } \\
\text { disorder. }\end{array}$ & $39(12)$ & $27(6)$ & $36(12)$ & $26(5)$ & MP & $\begin{array}{l}\text { Pre vs post } \\
\text { treatment }\end{array}$ & $\mathrm{N} / \mathrm{A}$ & AWS & PDH & MPOS \\
\hline 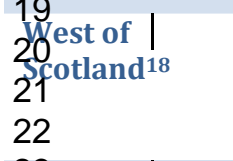 & $\begin{array}{l}\mathrm{W} / \text { in } \\
\text { subjects }\end{array}$ & $\underline{\text { IV }}$ & 12 & $\begin{array}{l}\text { Existing cohort of } \\
\text { children in study of } \\
\text { RAD; consecutive } \\
\text { groups }\end{array}$ & $\begin{array}{l}\text { "6-9 } \\
\text { years" }\end{array}$ & $\mathrm{N} / \mathrm{R}$ & $\mathrm{N} / \mathrm{A}$ & $\mathrm{N} / \mathrm{A}$ & MP & $\begin{array}{l}\text { Pre vs post } \\
\text { treatment }\end{array}$ & $\mathrm{N} / \mathrm{A}$ & HADS & $\begin{array}{l}\text { SDQ } \\
\text { PHS }\end{array}$ & MPOS \\
\hline $\begin{array}{l}23 \text { Peterspurg, } \\
24 \text { ussia }^{22}\end{array}$ & $\begin{array}{l}\text { Case- } \\
\text { control }\end{array}$ & $\underline{\text { IV }}$ & $16(15)$ & $\begin{array}{l}\text { Socially disadvantaged } \\
\text { mothers }\end{array}$ & $\mathrm{N} / \mathrm{R}$ & $\mathrm{N} / \mathrm{R}$ & $\mathrm{N} / \mathrm{R}$ & $\mathrm{N} / \mathrm{R}$ & MP & $\begin{array}{l}\text { Pre vs post } \\
\text { treatment }\end{array}$ & $\begin{array}{l}\text { Waiting list } \\
\text { control }\end{array}$ & EPDS & RBC & - \\
\hline $\begin{array}{l}\text { 25ungannon, } \\
26 \text { orthern } \\
2^{2} \text { eland }{ }^{27} \\
28 \\
29 \\
30 \\
31\end{array}$ & $\begin{array}{l}\text { W/in } \\
\text { subjects }\end{array}$ & $\underline{\text { IV }}$ & 7 & $\begin{array}{l}\text { Mothers with >1 risk: } \\
\text { domestic violence, } \\
\text { child protection } \\
\text { concerns, difficulties in } \\
\text { relationship with } \\
\text { child; history of mental } \\
\text { health or substance } \\
\text { misuse issues }\end{array}$ & $\mathrm{N} / \mathrm{R}$ & $\mathrm{N} / \mathrm{R}$ & $\mathrm{N} / \mathrm{A}$ & $\mathrm{N} / \mathrm{A}$ & MP & $\begin{array}{l}\text { Pre vs post } \\
\text { treatment }\end{array}$ & N/A & WEMWBS & $\mathrm{N} / \mathrm{A}$ & - \\
\hline $\begin{array}{l}\text { 32. } \\
\text { 33oigavoph, } \\
34 \text { eland } 27 \\
35 \\
36 \\
37 \\
38\end{array}$ & $\begin{array}{l}\mathrm{W} / \text { in } \\
\text { subjects }\end{array}$ & $\underline{\text { IV }}$ & 8 & $\begin{array}{l}\text { Mothers with }>1 \text { risk: } \\
\text { domestic violence, } \\
\text { child protection } \\
\text { concerns, difficulties in } \\
\text { relationship with } \\
\text { child; history of mental } \\
\text { health or substance } \\
\text { misuse issues }\end{array}$ & $\mathrm{N} / \mathrm{R}$ & $\mathrm{N} / \mathrm{R}$ & $\mathrm{N} / \mathrm{A}$ & $\mathrm{N} / \mathrm{A}$ & MP & $\begin{array}{l}\text { Pre vs post } \\
\text { treatment }\end{array}$ & $\mathrm{N} / \mathrm{A}$ & WEMWBS & N/A & - \\
\hline $\begin{array}{l}39 \\
4 \text { ewry, } \\
40 \text { orthern } \\
41 \text { eland } 27 \\
42 \\
43 \\
44 \\
45\end{array}$ & $\begin{array}{l}\mathrm{W} / \mathrm{in} \\
\text { subjects }\end{array}$ & $\underline{\text { IV }}$ & 13 & $\begin{array}{l}\text { Mothers with >1 risk: } \\
\text { domestic violence, } \\
\text { child protection } \\
\text { concerns, difficulties in } \\
\text { relationship with } \\
\text { child; history of mental } \\
\text { health or substance }\end{array}$ & $N / R$ & $\mathrm{~N} / \mathrm{R}$ & $\mathrm{N} / \mathrm{A}$ & $\mathrm{N} / \mathrm{A}$ & MP & $\begin{array}{l}\text { Pre vs post } \\
\text { treatment }\end{array}$ & $\mathrm{N} / \mathrm{A}$ & WEMWBS & $\mathrm{N} / \mathrm{A}$ & - \\
\hline
\end{tabular}




\begin{tabular}{|c|c|c|c|c|c|c|c|c|c|c|c|c|c|c|}
\hline 3 & & & & misuse issues & & & & & & & & & & \\
\hline $\begin{array}{l}\text { Aotearoa, New } \\
4 \text { ealand } 26 \\
6\end{array}$ & $\begin{array}{l}\text { Stepped } \\
\text { wedge } \\
\text { design }\end{array}$ & $\underline{\text { IV }}$ & 39 & $\begin{array}{l}\text { Maori mothers } \\
\text { experiencing } \\
\text { relationship and child } \\
\text { behaviour difficulties }\end{array}$ & $\mathrm{N} / \mathrm{R}$ & $\begin{array}{l}28.6 \\
(8.2)\end{array}$ & $\mathrm{N} / \mathrm{R}$ & $\mathrm{N} / \mathrm{R}$ & MP & $\begin{array}{l}\text { Pre vs post } \\
\text { treatment }\end{array}$ & $\begin{array}{l}\text { Data } \\
\text { unavailable } \\
\text { on controls }\end{array}$ & $\mathrm{N} / \mathrm{A}$ & SDQ & - \\
\hline $\begin{array}{l}\text { TLanarkshire, } \\
8 \text { cotland } 24 \\
9\end{array}$ & $\begin{array}{l}\text { Case- } \\
\text { control }\end{array}$ & $\underline{\text { III }}$ & $19(8)$ & $\begin{array}{l}\text { Mothers scoring above } \\
\text { cut-off on EPDS at } 12- \\
16 \text { weeks post-partum }\end{array}$ & $\mathrm{N} / \mathrm{R}$ & $\mathrm{N} / \mathrm{R}$ & $\mathrm{N} / \mathrm{R}$ & $\mathrm{N} / \mathrm{R}$ & MB & $\begin{array}{l}\text { Pre vs post } \\
\text { treatment }\end{array}$ & $\begin{array}{l}\text { Waiting list } \\
\text { control }\end{array}$ & EPDS & N/A & MPOS \\
\hline $\begin{array}{l}\text { 10 Petersburg, } \\
\text { Russia } 23\end{array}$ & $\begin{array}{l}\text { Case- } \\
\text { control }\end{array}$ & $\underline{\text { IV }}$ & $14(12)$ & $\begin{array}{l}\text { Socially disadvantaged } \\
\text { mothers }\end{array}$ & $\mathrm{N} / \mathrm{R}$ & $\mathrm{N} / \mathrm{R}$ & $\mathrm{N} / \mathrm{R}$ & $\mathrm{N} / \mathrm{R}$ & MB & $\begin{array}{l}\text { Pre vs post } \\
\text { treatment }\end{array}$ & $\mathrm{N} / \mathrm{A}$ & EPDS & $\mathrm{N} / \mathrm{A}$ & - \\
\hline
\end{tabular}

Notes: AWS - Adult Wellbeing Scale; EPDS - Edinburgh Postnatal Depression Scale; HADS; MB - Mellow Babies; MP - Mellow Parenting; MPOS - Mellow Parenting Observation Scale; N/A - Not applicable; N/R - Not Reported; PHS - Parental Hassles Scale; RAD - Reactive Attachment Disorder; RBC - Richman Behaviour Checklist; SDQ - Strengths and Difficulties Questionnaire; WEMWBS - Warwick-Edinburgh Mental Well-Being Scale; W/in subjects - Within subjects; * Level of Evidence applied using the AACPDM guidelines for quality in group studies. 
MP meta analysis

Draft 3.2

$09 / 03 / 14$

Supplemental Table 1: Risk of bias in individual studies (for online only publication)

\begin{tabular}{|c|c|c|c|c|c|c|}
\hline Study & $\begin{array}{l}\text { Blinding of } \\
\text { assessors? }\end{array}$ & $\begin{array}{l}\text { Treatment and } \\
\text { control groups similar } \\
\text { at baseline? }\end{array}$ & $\begin{array}{l}\text { Drop-out rate from referral } \\
\text { to start of intervention }\end{array}$ & $\begin{array}{l}\text { Drop out rate at post- } \\
\text { intervention? }\end{array}$ & $\begin{array}{l}\text { Statement of study } \\
\text { funding }\end{array}$ & Ethical Approval? \\
\hline $\begin{array}{l}\text { Puckering et al., } \\
1999 \text { (DoH) }\end{array}$ & No & Case-Control & $\mathrm{N} / \mathrm{R}$ & $\begin{array}{l}22 \% \text { for cases } / 4 \% \text { in } \\
\text { controls }\end{array}$ & $\begin{array}{l}\text { Yes - UK Department } \\
\text { of Health funding }\end{array}$ & Yes \\
\hline $\begin{array}{l}\text { Puckering et al., } \\
2011\end{array}$ & No & Not applicable & $50 \%$ & $0 \%$ & $\begin{array}{l}\text { Yes via reference to } \\
\text { Minnis et al (2009). } \\
\text { Chief Scientist's } \\
\text { Office of the Scottish } \\
\text { Government }\end{array}$ & $\begin{array}{l}\text { Yes - Multicentre } \\
\text { Research Ethics } \\
\text { Committee for } \\
\text { Scotland }\end{array}$ \\
\hline $\begin{array}{l}\text { Borjeson et al., } \\
2008\end{array}$ & No & Case-control & $? ?$ & Not available & Not available & $\mathrm{N} / \mathrm{R}$ \\
\hline SHSCT,2011 & No & Not applicable & $50 \%$ & $29 \%$ & $\begin{array}{l}\text { Yes - Northern } \\
\text { Ireland Public Health } \\
\text { Agency }\end{array}$ & $\begin{array}{l}\text { No - results reported } \\
\text { as routine data use. } \\
\text { Independent steering } \\
\text { group. }\end{array}$ \\
\hline SHSC., 2011 & No & Not applicable & $60 \%$ & $12.5 \%$ & $\begin{array}{l}\text { Yes - Northern } \\
\text { Ireland Public Health } \\
\text { Agency }\end{array}$ & $\begin{array}{l}\text { No - results reported } \\
\text { as routine data use. } \\
\text { Independent steering } \\
\text { group. }\end{array}$ \\
\hline SHSCT, 2011 & No & Not applicable & $43 \%$ & $23 \%$ & $\begin{array}{l}\text { Yes - Northern } \\
\text { Ireland Public Health } \\
\text { Agency }\end{array}$ & $\begin{array}{l}\text { No - results reported } \\
\text { as routine data use. } \\
\text { Independent steering } \\
\text { group. }\end{array}$ \\
\hline $\begin{array}{l}\text { Penehira \& } \\
\text { Doherty, } 2013\end{array}$ & No & Stepped wedge design & $13 \%$ & $20 \%$ & $\begin{array}{l}\text { Yes - New Zealand } \\
\text { Counties of Manukau } \\
\text { DHB }\end{array}$ & $\begin{array}{l}\text { Yes - Northern X } \\
\text { Regional Ethics } \\
\text { Committee }\end{array}$ \\
\hline $\begin{array}{l}\text { Puckering et al., } \\
2010\end{array}$ & No & Case-control & $\mathrm{N} / \mathrm{R}$ & $\begin{array}{l}\text { MB: } 9 \% \\
\text { Control: } 34 \%\end{array}$ & $\begin{array}{l}\text { Yes - Scottish } \\
\text { Government National } \\
\text { Programme for } \\
\text { Improving Mental } \\
\text { Health and Well- } \\
\text { Being (2005-2006) }\end{array}$ & $\begin{array}{l}\text { Yes: Lanarkshire } \\
\text { Local Research Ethics } \\
\text { Committee. }\end{array}$ \\
\hline $\begin{array}{l}\text { Morozova et al., } \\
2008\end{array}$ & No & Case-control & $\mathrm{N} / \mathrm{R}$ & $\mathrm{N} / \mathrm{R}$ & Not available & $\mathrm{N} / \mathrm{R}$ \\
\hline
\end{tabular}

Notes: Additional information on Penehira \& Doherty retrieved from https://www.anzctr.org.au/Trial/Registration/TrialReview.aspx?id=83548 on

01/10/14; N/R - Not Reported

Mac Keith Press 
| SupplementalTable 2: Studies included in meta analysis (online only publication)

\begin{tabular}{|c|c|c|c|c|c|c|c|c|c|c|c|c|}
\hline \multirow{3}{*}{$\begin{array}{l}\text { Study } \\
\text { Intervention }\end{array}$} & \multicolumn{6}{|c|}{ Parental Mental Health outcome Measure } & \multicolumn{6}{|c|}{ Child -based outcome Measure } \\
\hline & \multicolumn{3}{|c|}{ Pre-intervention } & \multicolumn{3}{|c|}{ Post-intervention } & \multicolumn{3}{|c|}{ Pre-intervention } & \multicolumn{3}{|c|}{ Post-intervention } \\
\hline & $\mathbf{n}$ & mean & sd & $\mathbf{n}$ & mean & sd & $\mathbf{n}$ & mean & sd & n & mean & sd \\
\hline Puckering et al., 1999 & 42 & 19.3 & 7.8 & 42 & 12.0 & 8.5 & 44 & 24.7 & 11.3 & 44 & 21.7 & 5.3 \\
\hline Puckering et al., $201 \underline{0}$ & 12 & 18.3 & 6.3 & 12 & 14.3 & 7.6 & 12 & 21.2 & 6.8 & 12 & 19.4 & 4.5 \\
\hline Boreson et al., 2008 & 16 & 8.9 & 5.4 & 16 & 6.4 & 4.2 & 15 & 4.0 & 3.2 & 15 & 2.9 & 3.3 \\
\hline SHSCT, 2011 & 4 & 47.5 & 6.8 & 4 & 54.3 & 6.8 & - & - & - & - & - & - \\
\hline SHSCT, 2011 & 6 & 27.2 & 24.6 & 6 & 51.8 & 24.6 & - & - & - & - & - & - \\
\hline SHSCT, 2011 & 10 & 39.7 & 10.3 & 10 & 50 & 10.3 & - & - & - & - & - & - \\
\hline Penehira \& Doherty, 2013 & 39 & 12.0 & 1.7 & 39 & 3.4 & 0.9 & 26 & 15.8 & 6.2 & 26 & 12.0 & 5.1 \\
\hline Puckering et al., 2010 & 11 & 18.8 & 4.7 & 11 & 11.2 & 5.9 & - & - & - & - & - & - \\
\hline Morozova et al., 2011 & 14 & 7.1 & 3.6 & 14 & 7.71 & 3.2 & 5 & 2.4 & 2.3 & 5 & 1.2 & 0.8 \\
\hline & & & & & & & & & & & & \\
\hline \multicolumn{13}{|l|}{ Controls } \\
\hline Puckering et al., 1999 (DoH) & 23 & 13.1 & 7.3 & 23 & 8.8 & 4.9 & 28 & 18.9 & 4.9 & 28 & 20.0 & 4.4 \\
\hline Borjeson et al., 2008 & 15 & 6.1 & 4.8 & 15 & 6.5 & 4.0 & 15 & 2.7 & 2.2 & 15 & 1.9 & 1.6 \\
\hline Puckering et al., 2010 & 5 & 17.8 & 4.8 & 5 & 19.6 & 4.0 & - & - & - & - & - & - \\
\hline Morozova et al., 2011 & 12 & 7.9 & 5.8 & 12 & 8.5 & 5.1 & 11 & 2.4 & 1.7 & 11 & 1.9 & 2.1 \\
\hline
\end{tabular}


MP meta analysis

Draft 3.2

09/03/14

Figure 1: PRISMA diagram of study identification

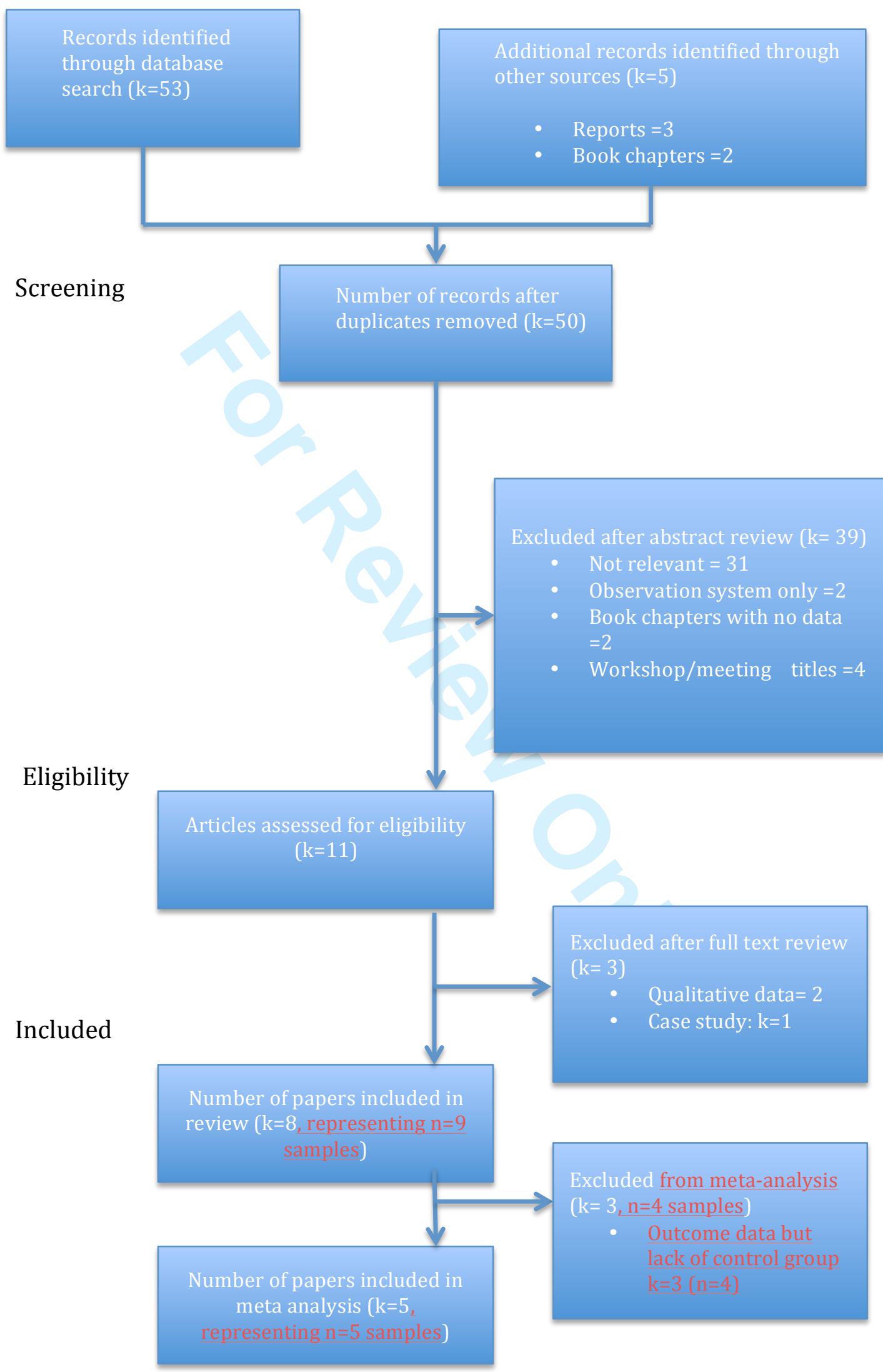

Mac Keith Press 
MP meta analysis

Draft 3.2

$09 / 03 / 14$

Figure 2: Meta analysis for effect of Mellow Parenting on parental wellbeing

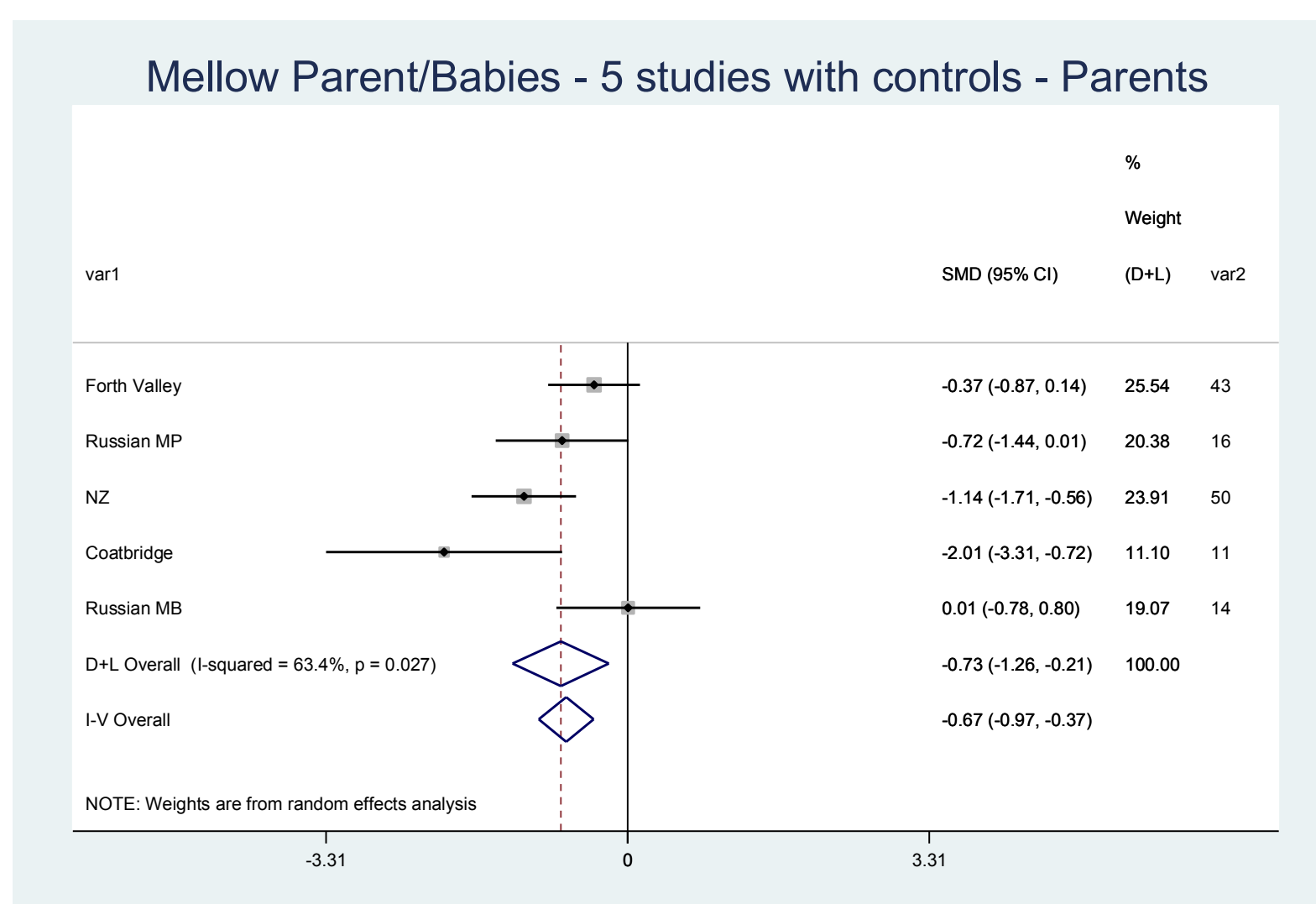

Mac Keith Press 


\section{Page 23 of 23}

MP meta analysis

$09 / 03 / 14$

Figure 3: Meta analysis for effect of Mellow Parenting on child outcomes

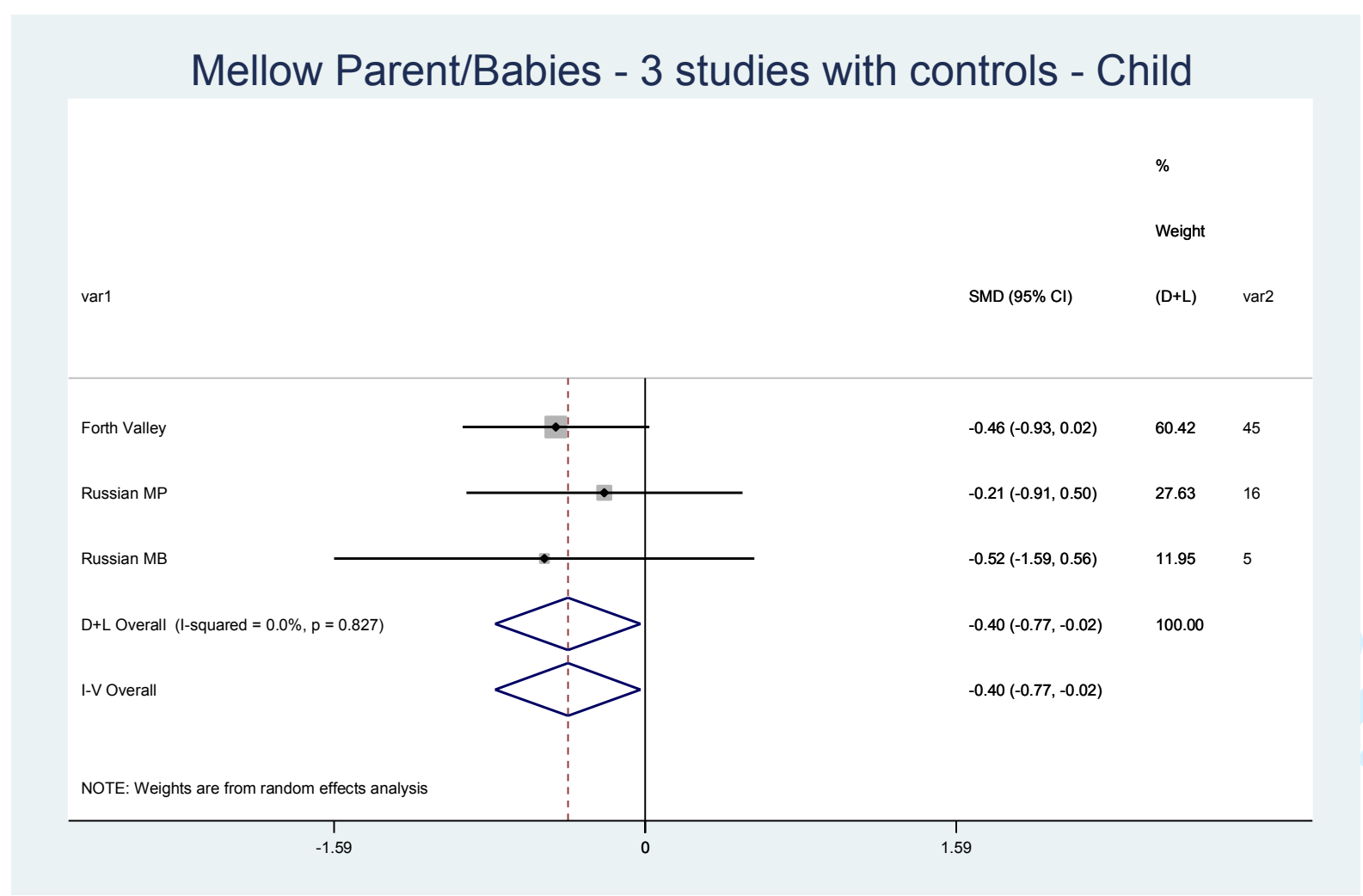

Mac Keith Press 